Review Article

\title{
Rho-Kinase/ROCK as a Potential Drug Target for Vitreoretinal Diseases
}

\author{
Muneo Yamaguchi, Shintaro Nakao, Mitsuru Arima, Iori Wada, Yoshihiro Kaizu, Feng Hao, \\ Shigeo Yoshida, and Koh-hei Sonoda
}

Department of Ophthalmology, Graduate School of Medical Sciences, Kyushu University, 3-1-1 Maidashi, Higashi-Ku,
Fukuoka 812-8582, Japan

Correspondence should be addressed to Shintaro Nakao; snakao@med.kyushu-u.ac.jp

Received 3 February 2017; Accepted 18 April 2017; Published 17 May 2017

Academic Editor: Naoshi Kondo

Copyright ( 2017 Muneo Yamaguchi et al. This is an open access article distributed under the Creative Commons Attribution License, which permits unrestricted use, distribution, and reproduction in any medium, provided the original work is properly cited.

\begin{abstract}
Rho-associated kinase (Rho-kinase/ROCK) was originally identified as an effector protein of the G protein Rho. Its involvement in various diseases, particularly cancer and cardiovascular disease, has been elucidated, and ROCK inhibitors have already been applied clinically for cerebral vasospasm and glaucoma. Vitreoretinal diseases including diabetic retinopathy, age-related macular degeneration, and proliferative vitreoretinoapthy are still a major cause of blindness. While anti-VEGF therapy has recently been widely used for vitreoretinal disorders due to its efficacy, attention has been drawn to new unmet needs. The importance of ROCK in pathological vitreoretinal conditions has also been elucidated and is attracting attention as a potential therapeutic target. ROCK is involved in angiogenesis and hyperpermeability and also in the pathogenesis of various pathologies such as inflammation and fibrosis. It has been expected that ROCK inhibitors will become new molecular target drugs for vitreoretinal diseases. This review summarizes the recent progress on the mechanisms of action of ROCK and their applications in disease treatment.
\end{abstract}

\section{Introduction}

Rho-associated kinase (Rho kinase/ROCK), identified as a Rho GTP-binding protein, is a downstream effector of the small GTP-binding protein Rho [1-5]. Two isoforms, ROCK1 (also known as ROK $\beta$ or p160ROCK) and ROCK2 (known as ROK $\alpha$ ), were isolated as Rho-A-GTP interacting proteins [6]. The Rho/ROCK signaling pathway is implicated in various cellular functions, such as cell proliferation, migration, and contraction [7], and has been reported to be crucial for cardiovascular diseases, central nervous disorders, and cancer. Therefore, ROCK has attracted attention as a therapeutic target for various diseases $[8,9]$. Recent studies have implicated Rho/ROCK signaling in both physiological and pathological ophthalmology [10] (Table 1). This review summarizes the recent progress on the role of Rho kinase/ROCK and its therapeutic potential in vitreoretinal diseases (Figure 1).

\section{Clinical Application of a ROCK Inhibitor}

Preclinical research has indicated that ROCK is an important molecule in the pathogenesis of cardiovascular diseases [11]. Based on these accumulated data, a selective ROCK inhibitor, fasudil, has been used in the clinical setting for cerebral vasospasm and ischemic stroke in Japan and China [12]. In ophthalmology, Honjo et al. have demonstrated lowering of intraocular pressure by ROCK inhibition in rabbits. This is the first report to show a therapeutic potential of ROCK inhibitor in eye disease [13]. In another study, a novel, potent, and selective ROCK inhibitor, ripasudil hydrochloride hydrate (K-115), could undergo a structural change and enhance the stearic affinity of the enzyme for ROCK [14]. The enzyme inhibitory effect of ripasudil is about five to ten times higher than that of the previous ROCK inhibitors such as fasudil 
TABLE 1: Comparison between VEGF and Rho/ROCK in disease pathogenesis.

\begin{tabular}{|c|c|c|}
\hline Biological process & VEGF inhibition & Rho/ROCK inhibition \\
\hline Ischemia & Possible induction of ischemia [24] & $\begin{array}{l}\text { Vascular normalization via pericyte coverage [45]; } \\
\text { vessel dilation [58]; } \\
\text { increased blood velocity and retinal blood flow [59] }\end{array}$ \\
\hline Angiogenesis & Antiangiogenesis $[81,82]$ & $\begin{array}{l}\text { Antiendothelial proliferation in vitro }[44,45] ; \\
\text { antiendothelial migration in vitro }[44,45] \text {; } \\
\text { antiangiogenesis in vivo retina }[43,45] \text {; antiangiogenesis } \\
\text { in vivo choroid }[63,66]\end{array}$ \\
\hline Hyperpermeability & Antipermeability $[83,84]$ & Antipermeability in choroidal neovascularization $[63,66]$ \\
\hline Inflammation & Antileukocyte trafficking [81]; antileukostasis [84] & Antileukostasis [38]; anti-M2 macrophage [63] \\
\hline Membrane contraction & $\begin{array}{l}\text { Possible induction of membrane contraction } \\
\text { and tractional retinal detachment [23]; } \\
\text { vessel contraction [25] }\end{array}$ & $\begin{array}{l}\text { Inhibition of membrane contraction in vivo }[50,73] \text {; } \\
\text { reduced collagen synthesis in RPE [66]; inhibition of gel } \\
\text { contraction by RPE }[72,73] \text {; anti-RPE proliferation }[72] \text {; } \\
\text { actin depolymerization in RPE [74] }\end{array}$ \\
\hline Neuronal damage & Possible induction of photoreceptor damage $[85,86]$ & Neuroprotection of RGC $[78,87,88]$ \\
\hline Fibrosis & Risk of inducible fibrosis $[22,65]$ & Antifibrosis in choroidal neovascularization [66] \\
\hline
\end{tabular}

and ripasudil which were clinically approved in 2014 as an eye drop for glaucoma in Japan [15].

\section{Unmet Needs in Vitreoretinal Diseases}

Vitreoretinal diseases are a common cause of blindness among working age adults $[16,17]$. Anti-VEGF administration is currently the most commonly used treatment option for wet age-related macular degeneration (AMD), macular edema secondary to retinal vein occlusion (RVO), and diabetic macular edema (DME) [18-20]. However, in addition to a need for repeated administration and the possibility of local or systemic adverse complications [21], its wide use is implicated in conditions beyond VEGF inhibition such as fibrosis in AMD, retinal ischemia, and fibrovascular membrane contraction in DR [22-25] (Table 1). Chronic anti-VEGF therapy may also increase medical expenses [26]. Therefore, novel therapies aside from VEGF are needed in the treatment of vitreoretinal diseases [27].

\section{ROCK as a Therapeutic Target for Diabetic Retinopathy}

4.1. Role of ROCK in Microvascular Complications in DR. While visual acuity is not always affected in nonproliferative stages of diabetic retinopathy (DR) without DME, DR progression can cause neovascularization, vitreous hemorrhages, preretinal fibrovascular proliferation, and tractional retinal detachment, which can lead to severe vision loss [28]. DR pathogenesis is accompanied by microvascular complications such as hyperpermeability, angiogenesis, microthrombosis, and inflammation [29, 30]. Diabetic retinal capillary disorder may be associated with retinal leukocyte stasis (leukostasis) at early nonproliferative stages of DR [31-34]. Leukostasis is mediated by adhesion molecules, intercellular adhesion molecule-1 (ICAM-1), and leukocyte $\beta 2$ integrins (CD18/CD11a and CD18/CD11b) $[31,35]$. ROCK pathway has been reported to regulate the expression and function of ICAM-1 in endothelial cells [36] and could be activated in vascular cells by serum from diabetic retinopathy patients [37]. This observation suggested that endothelial cells in diabetic retinopathy patients could be in a "ROCK-activated status" at the systemic level. Furthermore, a study with streptozotocin-induced diabetic model confirmed activation of the Rho/ROCK pathway in retinal microvessels [38]. Moreover, intravitreal fasudil significantly reduced ICAM-1 expression, leukocyte adhesion, and the number of damaged endothelial cells in retinas of diabetic rats [38] (Table 2). These data indicate that ROCK signaling plays important roles in the pathogenesis of microvascular complications in diabetic retinopathy, and its inhibition may represent a new strategy for managing early stage diabetic retinopathy, which is an observation period with no ophthalmic treatment.

4.2. Controversial Role of ROCK in Hyperpermeability and Angiogenesis. VEGF plays a critical role in the pathogenesis of DR-related hyperpermeability and angiogenesis [39]. While ROCK inhibition by Y27632 could block VEGFinduced endothelial hyperpermeability [40], the role of ROCK in TNF- $\alpha$-induced endothelial permeability is still controversial $[41,42]$. The effect of ROCK inhibitors on hyperpermeability in diabetic retinopathy may be different for each case. A ROCK inhibitor, Y27632, blocked VEGFinduced angiogenesis in an oxygen-induced retinopathy (OIR) model [43], while fasudil inhibited angiogenesis in corneal and OIR models [44, 45] (Table 2). In vitro, ROCK inhibition by fasudil significantly inhibited VEGF-induced retinal endothelial cell proliferation and migration in human and bovine retinal endothelial cells $[44,45]$. These previous data suggest that a mechanism of ROCK inhibition on VEGF-induced angiogenesis could be via blockade of endothelial migration and proliferation. In contrast, a study with a ROCK inhibitor H-1152 showed increased VEGF-induced angiogenesis in an OIR model and an in vitro sprouting model via ERK1/2 activation [46]. This discrepancy might be due to different drug affinities against the two ROCK isoforms or an unexpected nonspecific effect [47]. It has also 


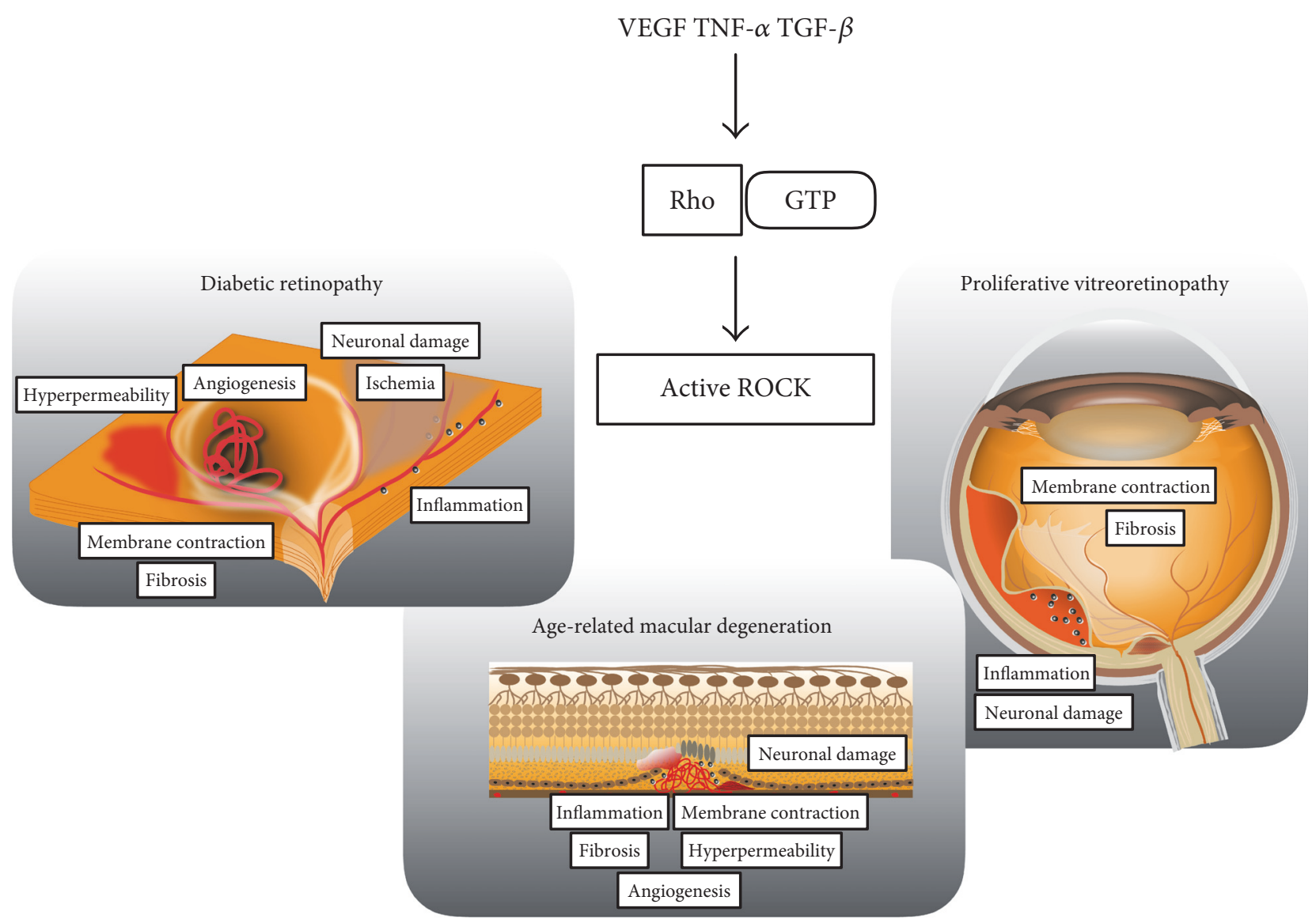

FIGURE 1: ROCK-activated vitreoretinal diseases. ROCK activation is involved in the pathology of retinal vitreous diseases such as diabetic retinopathy, age-related macular degeneration, and PVR, termed as "ROCK-activated diseases." In each disease, the Rho-ROCK signaling pathway is activated by various cytokines, implicating ROCK in various pathology. Therefore, ROCK is a potential therapeutic target for these vitreoretinal diseases.

TABLE 2: ROCK inhibitors in animal models of vitreoretinal diseases.

\begin{tabular}{|c|c|c|c|c|}
\hline Animal model & $\begin{array}{c}\text { OIR model } \\
\text { (oxygen-induced retinopathy) }\end{array}$ & $\begin{array}{c}\text { STZ model } \\
\text { (streptozotocin-induced } \\
\text { diabetes model) }\end{array}$ & $\begin{array}{c}\text { CNV model (choroidal } \\
\text { neovascularization model) }\end{array}$ & $\begin{array}{l}\text { PVR (proliferative } \\
\text { vitreoretinopathy model) }\end{array}$ \\
\hline Fasudil & Antiangiogenesis [45] & Antileukostasis [38] & $\begin{array}{l}\text { Antipermeability [63]; } \\
\text { anti-M2 macrophage [63]; } \\
\text { antiangiogenesis [63] }\end{array}$ & $\begin{array}{l}\text { Inhibition of membrane } \\
\text { contraction [50] }\end{array}$ \\
\hline Ripasudil (K115) & $\begin{array}{l}\text { Vascular normalization } \\
\text { via pericyte coverage [45]; } \\
\text { antiangiogenesis }[45]\end{array}$ & No report & No report & No report \\
\hline Y27632 & Antiangiogenesis [43] & No report & No report & $\begin{array}{l}\text { Inhibition of membrane } \\
\text { contraction [73] }\end{array}$ \\
\hline AMA0428 & $\begin{array}{l}\text { Antiangiogenesis [89]; } \\
\text { inhibition neuronal cell } \\
\text { death [89] }\end{array}$ & $\begin{array}{c}\text { Antileukostasis [89]; } \\
\text { antipermeability [89]; } \\
\text { neuroprotection of RGC [89] }\end{array}$ & $\begin{array}{l}\text { Antiangiogenesis [66]; } \\
\text { antifibrosis [66]; } \\
\text { antiinflamation [66] }\end{array}$ & No report \\
\hline
\end{tabular}

been reported that ROCK signaling could upregulate VEGF in diabetic retina [48].

4.3. ROCK as a Therapeutic Target in Proliferative Membrane. In the later stages of DR, epiretinal fibrovascular membranes that form along with retinal neovascularization contract and result in traction retinal detachment (TRD)
[49]. ROCK inhibition effectively disrupted $\alpha$-SMA organization and blocked contraction of the proliferative membrane in an in vivo experimental rabbit model [50] (Table 2). In hyalocyte-containing collagen gel assays, ROCK inhibition almost completely abolished PDR vitreous-induced collagen gel contraction mediated through MLC phosphorylation suppression $[50,51]$. 
4.4. Involvement of ROCK Different from VEGF in Diabetic Macular Edema. Diabetes reduces occludin quantity at tight junctions in retinal endothelial cells and causes tight junction protein disorganization in retinal arterioles and capillaries [52], presumably leading to vascular hyperpermeability and DME. The Rho/ROCK pathway has been associated with tight junction protein degradation and blood-brain barrier disruption [53]. Furthermore, recent clinical observations suggested that combination therapy of bevacizumab and fasudil intravitreal injection was effective based on structural and functional outcomes in eyes with severe DME that were resistant to current anti-VEGF therapy [54, 55], indicating that ROCK inhibition is mechanistically different from anti-VEGF therapy.

4.5. ROCK Inhibition for Retinal Ischemia. Currently, there is no effective treatment for microthrombosis and retinal ischemia. Although laser photocoagulation has been used to treat diabetic retinopathy patients with ischemic retinal tissue, this treatment could cause several adverse events including night blindness. A recent paper showed ROCK inhibition by ripasudil could cause intraretinal vascularization while inhibiting preretinal angiogenesis, leading to reduced hypoxic area in an OIR model [45]. Furthermore, the ripasudil treatment could improve retinal vascular perfusion and induce pericyte coverage [45] (Table 2). This phenomenon could be the vascular normalization that has been proposed in cancer research [56]. However, further investigation using other ROCK inhibitors would be necessary to validate the induction of vascular normalization. Fasudil has already been shown to improve ischemia in patients with acute ischemic stroke [57]. It has been previously reported that ROCK inhibition could cause retinal vessel dilation, and this in turn could contribute to ischemia improvement [58]. A recent study in cats showed that intravitreal ripasudil injection could significantly increase retinal blood velocity and flow [59]. ROCK inhibition may therefore be a new therapeutic strategy for retinal ischemia in retinal vascular disorders.

\section{ROCK as a Therapeutic Target for Age-Related Macular Degeneration}

5.1. ROCK2-Mediated Macrophage Polarization in Aging. There are two types of AMD, a dry form that ultimately leads to macular atrophy and a wet and exudative form characterized by choroidal neovascularization $(\mathrm{CNV})$ and leakage [60]. The pathogenesis of AMD remains incompletely understood. Macrophages are found in CNV lesions and have been reported to promote and inhibit CNV [61, 62]. This phenotype-associated mechanism was unknown. Furthermore, it was also unclear how aging promotes the pathogenesis. A recent paper by Zandi et al. showed that macrophage polarization was triggered by ROCK2 signaling, which is increased with age, and a shift of the fundus microenvironment through selective ROCK2 inhibition improved the pathology [63] (Table 2).
5.2. ROCK as a Possible Target in Subretinal Fibrosis. Wet AMD-related CNV eventually causes fibrosis that could lead to irreversible vision loss $[64,65]$, and there is currently no effective treatment for this fibrosis. A ROCK inhibitor, AMA0428, was recently reported to be effective in reducing fibrosis in a mouse CNV model [66] (Table 2). As the Rho/ ROCK pathway is a downstream signaling of fibrotic disease drivers, such as TGF- $\beta[67,68]$, ROCK inhibition might block TGF- $\beta$-related subretinal fibrosis although the detailed mechanism is still unknown. ROCK inhibition may therefore be a new therapy for fibrosis and neovascularization in AMD.

\section{ROCK as a Therapeutic Target for Proliferative Vitreoretinopathy}

Proliferative vitreoretinopathy (PVR) is the leading cause of failure after retinal detachment surgery. PVR is characterized by the growth and contraction of cellular membranes within the hyaloid and retina and on both retinal surfaces following retinal reattachment surgery [69]. Retinal detachment allows macrophages, retinal pigment epithelial (RPE) cells, glial cells, and fibroblasts to migrate to the vitreous, where they proliferate, survive, form extracellular matrix proteins, and assemble into a membrane [70]. Some studies suggest that cytokines such as TGF- $\beta 2$ and PDGF contribute to PVR pathogenesis [71]. However, there is currently no effective treatment other than surgery. Various recent papers have shown that the ROCK pathway is involved in PVR pathogenesis. The importance of ROCK for TGF- $\beta$-induced gel contraction by retinal pigment epithelium has been reported [67, 72-74]. Furthermore, in vivo studies suggest that ROCK inhibition could block TRD development $[50,73]$ and that ROCK inhibitors might aid in PVR prevention and development apart from vitrectomy surgery [75] (Table 2).

\section{Future Directions of ROCK Inhibitors: Neuroprotection}

Microvascular changes underlie DR and AMD, while histological studies have characterized the loss of neurons [76]. The roles of neural retinal alterations in the pathogenesis of early retinopathy and the mechanisms of vision loss have been emphasized [77]. A recent report has demonstrated that administration of an oral ROCK inhibitor, K115, delayed RGC death [78]. Fasudil also resulted in ischemia-related apoptosis of retinal cells by inhibiting Bax/Bcl-2, caspase-3, and iNOS in rats [79]. However, the importance of ROCK for neural degeneration in vitreoretinal diseases including $\mathrm{DR}$ and AMD is unknown. Future investigations are expected to demonstrate a therapeutic potential of ROCK inhibitors in vitreoretinal disorders.

\section{Future Directions of ROCK Inhibitors: Beyond VEGF}

In summary, some disease states extend beyond VEGF inhibition, including fibrosis in AMD, retinal ischemia, retinal neuropathy, and fibrovascular membrane contraction in 
DR (Table 1). ROCK inhibition may be effective in these pathological conditions. A previous study using radiolabeled drug revealed that ripasudil could reach the retina and choroid after eye drop administration in rabbits [14]. If proven effective, topical ophthalmic treatment would be beneficial for patients with vitreoretinal diseases. Furthermore, the role of ROCK isoforms in vitreoretinal diseases is unclear. In a recent paper, a ROCK2 inhibitor, but not the pan-ROCK inhibitor fasudil, was beneficial in age-related immune changes in AMD [63]. Intensive investigation is needed to elucidate the role of ROCK isoforms in the pathogenesis of these vitreoretinal diseases.

\section{Conclusion}

The clinical application of anti-VEGF therapy and its success constitutes the beginning of the era of molecular targeting drugs in ophthalmology. Currently, various molecular targeting drugs are under clinical trials for vitreoretinal diseases [80]. Several will be clinically applied in the near future, and these are expected to impact the therapeutic strategy of vitreoretinal diseases. ROCK could be one of these potential drug targets. An optimal administration method/administration protocol is expected to emerge based on both clinical and nonclinical investigations.

\section{Conflicts of Interest}

Shintaro Nakao and Tatsuro Ishibashi have conflicting interests of Kowa (Patent). The other authors declare that there is no conflict of interest regarding the publication of this paper.

\section{References}

[1] M. Amano, M. Nakayama, and K. Kaibuchi, "Rho-kinase/ ROCK: a key regulator of the cytoskeleton and cell polarity," Cytoskeleton (Hoboken), vol. 67, no. 9, pp. 545-554, 2010.

[2] E. Sahai, T. Ishizaki, S. Narumiya, and R. Treisman, "Transformation mediated by RhoA requires activity of ROCK kinases," Current Biology, vol. 9, no. 3, pp. 136-145, 1999.

[3] T. Matsui, M. Amano, T. Yamamoto et al., "Rho-associated kinase, a novel serine/threonine kinase, as a putative target for small GTP binding protein Rho," The EMBO Journal, vol. 15, no. 9, pp. 2208-2216, 1996.

[4] T. Ishizaki, M. Maekawa, K. Fujisawa et al., "The small GTP-binding protein Rho binds to and activates a $160 \mathrm{kDa}$ Ser/Thr protein kinase homologous to myotonic dystrophy kinase," The EMBO Journal, vol. 15, no. 8, pp. 18851893, 1996.

[5] T. Leung, X. Q. Chen, E. Manser, and L. Lim, "The p160 RhoA-binding kinase ROK alpha is a member of a kinase family and is involved in the reorganization of the cytoskeleton," Molecular and Cellular Biology, vol. 16, no. 10, pp. 5313-5327, 1996.

[6] O. Nakagawa, K. Fujisawa, T. Ishizaki, Y. Saito, K. Nakao, and S. Narumiya, "ROCK-I and ROCK-II, two isoforms of Rhoassociated coiled-coil forming protein serine/threonine kinase in mice," FEBS Letters, vol. 392, no. 2, pp. 189-193, 1996.
[7] H. Shimokawa and A. Takeshita, "Rho-kinase is an important therapeutic target in cardiovascular medicine," Arteriosclerosis, Thrombosis, and Vascular Biology, vol. 25, no. 9, pp. 1767-1775, 2005.

[8] B. K. Mueller, H. Mack, and N. Teusch, "Rho kinase, a promising drug target for neurological disorders," Nature Reviews. Drug Discovery, vol. 4, no. 5, pp. 387-398, 2005.

[9] N. Rath and M. F. Olson, "Rho-associated kinases in tumorigenesis: re-considering ROCK inhibition for cancer therapy," EMBO Reports, vol. 13, no. 10, pp. 900-908, 2012.

[10] A. Futakuchi, T. Inoue, T. Fujimoto, M. Inoue-Mochita, M. Kawai, and H. Tanihara, "The effects of ripasudil (K-115), a Rho kinase inhibitor, on activation of human conjunctival fibroblasts," Experimental eye Research, vol. 149, pp. 107$115,2016$.

[11] H. Shimokawa, "Rho-kinase as a novel therapeutic target in treatment of cardiovascular diseases," Journal of Cardiovascular Pharmacology, vol. 39, no. 3, pp. 319-327, 2002.

[12] M. Shibuya, Y. Suzuki, K. Sugita et al., "Effect of AT877 on cerebral vasospasm after aneurysmal subarachnoid hemorrhage. Results of a prospective placebo-controlled doubleblind trial," Journal of Neurosurgery, vol. 76, no. 4, pp. 571-577, 1992.

[13] M. Honjo, H. Tanihara, M. Inatani et al., "Effects of Rhoassociated protein kinase inhibitor Y-27632 on intraocular pressure and outflow facility," Investigative Ophthalmology \& Visual Science, vol. 42, no. 1, pp. 137-144, 2001.

[14] T. Isobe, K. Mizuno, Y. Kaneko, M. Ohta, T. Koide, and S. Tanabe, "Effects of K-115, a Rho-kinase inhibitor, on aqueous humor dynamics in rabbits," Current eye Research, vol. 39, no. 8, pp. 813-822, 2014.

[15] H. Tanihara, T. Inoue, T. Yamamoto et al., "Additive intraocular pressure-lowering effects of the Rho kinase inhibitor Ripasudil (K-115) combined with Timolol or Latanoprost: a report of 2 randomized clinical trials," JAMA Ophthalmology, vol. 133, no. 7, pp. 755-761, 2015.

[16] S. Sivaprasad, B. Gupta, R. Crosby-Nwaobi, and J. Evans, "Prevalence of diabetic retinopathy in various ethnic groups: a worldwide perspective," Survey of Ophthalmology, vol. 57, no. 4, pp. 347-370, 2012.

[17] D. S. Friedman, B. J. O'Colmain, B. Munoz et al., "Prevalence of age-related macular degeneration in the United States," Archives of Ophthalmology, vol. 122, no. 4, pp. 564-572, 2004.

[18] Group CR, D. F. Martin, M. G. Maguire et al., "Ranibizumab and bevacizumab for neovascular age-related macular degeneration," The New England Journal of Medicine, vol. 364, no. 20, pp. 1897-1908, 2011.

[19] P. Mitchell, F. Bandello, U. Schmidt-Erfurth et al., "The RESTORE study: ranibizumab monotherapy or combined with laser versus laser monotherapy for diabetic macular edema," Ophthalmology, vol. 118, no. 4, pp. 615-625, 2011.

[20] D. M. Brown, P. A. Campochiaro, R. P. Singh et al., "Ranibizumab for macular edema following central retinal vein occlusion: six-month primary end point results of a phase III study," Ophthalmology, vol. 117, no. 6, pp. 1124-1133, 2010, e1121.

[21] C. Shima, H. Sakaguchi, F. Gomi et al., "Complications in patients after intravitreal injection of bevacizumab," Acta Ophthalmologica, vol. 86, no. 4, pp. 372-376, 2008. 
[22] J. C. Hwang, L. V. Del Priore, K. B. Freund, S. Chang, and R. Iranmanesh, "Development of subretinal fibrosis after anti-VEGF treatment in neovascular age-related macular degeneration," Ophthalmic Surgery, Lasers \& Imaging, vol. 42, no. 1, pp. 6-11, 2011.

[23] J. F. Arevalo, M. Maia, H. W. Flynn Jr. et al., "Tractional retinal detachment following intravitreal bevacizumab (Avastin) in patients with severe proliferative diabetic retinopathy," The British Journal of Ophthalmology, vol. 92, no. 2, pp. 213-216, 2008.

[24] H. Enaida, K. Okamoto, H. Fujii, and T. Ishibashi, "LSFG findings of proliferative diabetic retinopathy after intravitreal injection of bevacizumab," Ophthalmic Surgery, Lasers \& Imaging, vol. 41, Online, pp. e1-e3, 2010.

[25] S. Nakao, K. Ishikawa, S. Yoshida et al., "Altered vascular microenvironment by bevacizumab in diabetic fibrovascular membrane," Retina, vol. 33, no. 5, pp. 957-963, 2013.

[26] E. L. Ross, D. W. Hutton, J. D. Stein et al., "Costeffectiveness of aflibercept, bevacizumab, and ranibizumab for diabetic macular edema treatment: analysis from the diabetic retinopathy clinical research network comparative effectiveness trial," JAMA Ophthalmology, vol. 134, no. 8, pp. 888-896, 2016.

[27] J. W. Miller, "Treatment of age-related macular degeneration: beyond VEGF," Japanese Journal of Ophthalmology, vol. 54, no. 6, pp. 523-528, 2010.

[28] J. Pe'er, D. Shweiki, A. Itin, I. Hemo, H. Gnessin, and E. Keshet, "Hypoxia-induced expression of vascular endothelial growth factor by retinal cells is a common factor in neovascularizing ocular diseases," Laboratory Investigation, vol. 72, no. 6, pp. 638-645, 1995.

[29] G. A. Lutty, "Effects of diabetes on the eye," Investigative Ophthalmology \& Visual Science, vol. 54, no. 14, pp. ORSF81ORSF87, 2013.

[30] S. H. Y. Nakao, "An overview of diabetes and ocular health," in Nutritional and Therapeutic Interventions of Diabetes and Metabolic Syndrome, pp. 159-176, Elsevier/Academic Press, Oxford, UK, 2012.

[31] K. Miyamoto, S. Khosrof, S. E. Bursell et al., "Prevention of leukostasis and vascular leakage in streptozotocin-induced diabetic retinopathy via intercellular adhesion molecule-1 inhibition," Proceedings of the National Academy of Sciences of the United States of America, vol. 96, no. 19, pp. 10836$10841,1999$.

[32] A. M. Joussen, T. Murata, A. Tsujikawa, B. Kirchhof, S. E. Bursell, and A. P. Adamis, "Leukocyte-mediated endothelial cell injury and death in the diabetic retina," The American Journal of Pathology, vol. 158, no. 1, pp. 147-152, 2001.

[33] K. Noda, S. Nakao, S. Ishida, and T. Ishibashi, "Leukocyte adhesion molecules in diabetic retinopathy," Journal of Ophthalmology, vol. 2012, Article ID 279037, 6 pages, 2012.

[34] K. Noda, S. Nakao, S. Zandi, D. Sun, K. C. Hayes, and A. Hafezi-Moghadam, "Retinopathy in a novel model of metabolic syndrome and type 2 diabetes: new insight on the inflammatory paradigm," The FASEB Journal, vol. 28, no. 5, pp. 2038-2046, 2014.

[35] F. C. Barouch, K. Miyamoto, J. R. Allport et al., "Integrinmediated neutrophil adhesion and retinal leukostasis in diabetes," Investigative Ophthalmology \& Visual Science, vol. 41, no. 5, pp. 1153-1158, 2000.
[36] K. N. Anwar, F. Fazal, A. B. Malik, and A. Rahman, "RhoA/Rho-associated kinase pathway selectively regulates thrombin-induced intercellular adhesion molecule-1 expression in endothelial cells via activation of I kappa B kinase beta and phosphorylation of RelA/p65," Journal of Immunology, vol. 173, no. 11, pp. 6965-6972, 2004.

[37] R. Arita, S. Nakao, T. Kita et al., "A key role for ROCK in TNF-alpha-mediated diabetic microvascular damage," Investigative Ophthalmology \& Visual Science, vol. 54, no. 3, pp. 2373-2383, 2013.

[38] R. Arita, Y. Hata, S. Nakao et al., "Rho kinase inhibition by fasudil ameliorates diabetes-induced microvascular damage," Diabetes, vol. 58, no. 1, pp. 215-226, 2009.

[39] A. P. Adamis and D. T. Shima, "The role of vascular endothelial growth factor in ocular health and disease," Retina, vol. 25, no. 2, pp. 111-118, 2005.

[40] H. Sun, J. W. Breslin, J. Zhu, S. Y. Yuan, and M. H. Wu, "Rho and ROCK signaling in VEGF-induced microvascular endothelial hyperpermeability," Microcirculation, vol. 13, no. 3, pp. 237-247, 2006.

[41] F. E. Nwariaku, P. Rothenbach, Z. Liu, X. Zhu, R. H. Turnage, and L. S. Terada, "Rho inhibition decreases TNF-induced endothelial MAPK activation and monolayer permeability," Journal of Applied Physiology (1985), vol. 95, no. 5, pp. 18891895, 2003.

[42] J. A. McKenzie and A. J. Ridley, "Roles of Rho/ROCK and MLCK in TNF-alpha-induced changes in endothelial morphology and permeability," Journal of Cellular Physiology, vol. 213, no. 1, pp. 221-228, 2007.

[43] X. Fang, M. Ueno, T. Yamashita, and Y. Ikuno, "RhoA activation and effect of Rho-kinase inhibitor in the development of retinal neovascularization in a mouse model of oxygeninduced retinopathy," Current eye Research, vol. 36, no. 11, pp. 1028-1036, 2011.

[44] Y. Hata, M. Miura, S. Nakao, S. Kawahara, T. Kita, and T. Ishibashi, "Antiangiogenic properties of fasudil, a potent Rho-kinase inhibitor," Japanese Journal of Ophthalmology, vol. 52, no. 1, pp. 16-23, 2008.

[45] M. Yamaguchi, S. Nakao, R. Arita et al., "Vascular normalization by ROCK inhibitor: therapeutic potential of ripasudil (K-115) eye drop in retinal angiogenesis and hypoxia," Investigative Ophthalmology \& Visual Science, vol. 57, no. 4, pp. 2264-2276, 2016.

[46] J. Kroll, D. Epting, K. Kern et al., "Inhibition of Rho-dependent kinases ROCK I/II activates VEGF-driven retinal neovascularization and sprouting angiogenesis," American Journal of Physiology. Heart and Circulatory Physiology, vol. 296, no. 3, pp. H893-H899, 2009.

[47] G. Mavria, Y. Vercoulen, M. Yeo et al., "ERK-MAPK signaling opposes Rho-kinase to promote endothelial cell survival and sprouting during angiogenesis," Cancer Cell, vol. 9, no. 1, pp. 33-44, 2006.

[48] T. Yokota, K. Utsunomiya, K. Taniguchi, A. Gojo, H. Kurata, and N. Tajima, "Involvement of the Rho/Rho kinase signaling pathway in platelet-derived growth factor BB-induced vascular endothelial growth factor expression in diabetic rat retina," Japanese Journal of Ophthalmology, vol. 51, no. 6, pp. 424430, 2007.

[49] D. K. Newman, "Surgical management of the late complications of proliferative diabetic retinopathy," Eye (London, England), vol. 24, no. 3, pp. 441-449, 2010. 
[50] T. Kita, Y. Hata, R. Arita et al., "Role of TGF-beta in proliferative vitreoretinal diseases and ROCK as a therapeutic target," Proceedings of the National Academy of Sciences of the United States of America, vol. 105, no. 45, pp. 17504-17509, 2008.

[51] T. Kita, Y. Hata, K. Kano et al., "Transforming growth factorbeta 2 and connective tissue growth factor in proliferative vitreoretinal diseases: possible involvement of hyalocytes and therapeutic potential of Rho kinase inhibitor," Diabetes, vol. 56, no. 1, pp. 231-238, 2007.

[52] T. Murakami, E. A. Felinski, and D. A. Antonetti, "Occludin phosphorylation and ubiquitination regulate tight junction trafficking and vascular endothelial growth factor-induced permeability," The Journal of Biological Chemistry, vol. 284, no. 31, pp. 21036-21046, 2009.

[53] A. C. Luissint, C. Artus, F. Glacial, K. Ganeshamoorthy, and P. O. Couraud, "Tight junctions at the blood brain barrier: physiological architecture and disease-associated dysregulation," Fluids and Barriers of the CNS, vol. 9, no. 1, p. 23, 2012.

[54] R. Nourinia, H. Ahmadieh, M. H. Shahheidari, S. Zandi, S. Nakao, and A. Hafezi-Moghadam, "Intravitreal fasudil combined with bevacizumab for treatment of refractory diabetic macular edema; a pilot study," Journal of Ophthalmic and Vision Research, vol. 8, no. 4, pp. 337-340, 2013.

[55] H. Ahmadieh, R. Nourinia, and A. Hafezi-Moghadam, "Intravitreal fasudil combined with bevacizumab for persistent diabetic macular edema: a novel treatment," JAMA Ophthalmology, vol. 131, no. 7, pp. 923-924, 2013.

[56] R. K. Jain, "Normalizing tumor microenvironment to treat cancer: bench to bedside to biomarkers," Journal of Clinical Oncology, vol. 31, no. 17, pp. 2205-2218, 2013.

[57] A. Masumoto, M. Mohri, H. Shimokawa, L. Urakami, M. Usui, and A. Takeshita, "Suppression of coronary artery spasm by the Rho-kinase inhibitor fasudil in patients with vasospastic angina," Circulation, vol. 105, no. 13, pp. 1545-1547, 2002.

[58] T. Nagaoka, T. W. Hein, A. Yoshida, and L. Kuo, "Simvastatin elicits dilation of isolated porcine retinal arterioles: role of nitric oxide and mevalonate-Rho kinase pathways," Investigative Ophthalmology \& Visual Science, vol. 48, no. 2, pp. 825832, 2007.

[59] S. Nakabayashi, M. Kawai, T. Yoshioka et al., "Effect of intravitreal Rho kinase inhibitor ripasudil (K-115) on feline retinal microcirculation," Experimental eye Research, vol. 139, pp. 132-135, 2015.

[60] L. G. Fritsche, R. N. Fariss, D. Stambolian, G. R. Abecasis, C. A. Curcio, and A. Swaroop, "Age-related macular degeneration: genetics and biology coming together," Annual Review of Genomics and Human Genetics, vol. 15, pp. 151-171, 2014.

[61] C. Tsutsumi, K. H. Sonoda, K. Egashira et al., "The critical role of ocular-infiltrating macrophages in the development of choroidal neovascularization," Journal of Leukocyte Biology, vol. 74, no. 1, pp. 25-32, 2003.

[62] R. S. Apte, J. Richter, J. Herndon, and T. A. Ferguson, "Macrophages inhibit neovascularization in a murine model of age-related macular degeneration," PLoS Medicine, vol. 3, no. 8, article e310, 2006.

[63] S. Zandi, S. Nakao, K. H. Chun et al., "ROCK-isoform-specific polarization of macrophages associated with age-related macular degeneration," Cell Reports, vol. 10, no. 7, pp. 11731186, 2015.

[64] R. O. Schlingemann, "Role of growth factors and the wound healing response in age-related macular degeneration,"
Graefe's Archive for Clinical and Experimental Ophthalmology, vol. 242, no. 1, pp. 91-101, 2004.

[65] E. Daniel, C. A. Toth, J. E. Grunwald et al., "Risk of scar in the comparison of age-related macular degeneration treatments trials," Ophthalmology, vol. 121, no. 3, pp. 656-666, 2014.

[66] K. Hollanders, T. Van Bergen, N. Kindt et al., "The effect of AMA0428, a novel and potent ROCK inhibitor, in a model of neovascular age-related macular degeneration," Investigative Ophthalmology \& Visual Science, vol. 56, no. 2, pp. 1335-1348, 2015.

[67] Y. Itoh, K. Kimoto, M. Imaizumi, and K. Nakatsuka, "Inhibition of RhoA/Rho-kinase pathway suppresses the expression of type I collagen induced by TGF-beta 2 in human retinal pigment epithelial cells," Experimental eye Research, vol. 84, no. 3, pp. 464-472, 2007.

[68] K. Ishikawa, R. Kannan, and D. R. Hinton, "Molecular mechanisms of subretinal fibrosis in age-related macular degeneration," Experimental eye Research, vol. 142, pp. 1925, 2016.

[69] S. J. Ryan, "The pathophysiology of proliferative vitreoretinopathy in its management," American Journal of Ophthalmology, vol. 100, no. 1, pp. 188-193, 1985.

[70] S. N. Moysidis, A. Thanos, and D. G. Vavvas, "Mechanisms of inflammation in proliferative vitreoretinopathy: from bench to bedside," Mediators of Inflammation, vol. 2012, Article ID 815937, 11 pages, 2012.

[71] C. H. Kon, N. L. Occleston, G. W. Aylward, and P. T. Khaw, "Expression of vitreous cytokines in proliferative vitreoretinopathy: a prospective study," Investigative Ophthalmology \& Visual Science, vol. 40, no. 3, pp. 705-712, 1999.

[72] M. Miura, Y. Hata, K. Hirayama et al., "Critical role of the Rho-kinase pathway in TGF-beta2-dependent collagen gel contraction by retinal pigment epithelial cells," Experimental eye Research, vol. 82, no. 5, pp. 849-859, 2006.

[73] Y. Zheng, H. Bando, Y. Ikuno et al., "Involvement of Rhokinase pathway in contractile activity of rabbit RPE cells in vivo and in vitro," Investigative Ophthalmology \& Visual Science, vol. 45, no. 2, pp. 668-674, 2004.

[74] J. Lee, M. Ko, and C. K. Joo, "Rho plays a key role in TGFbetal-induced cytoskeletal rearrangement in human retinal pigment epithelium," Journal of Cellular Physiology, vol. 216, no. 2, pp. 520-526, 2008.

[75] P. Wiedemann, N. Sorgente, and S. J. Ryan, "Proliferative vitreoretinopathy: the rabbit cell injection model for screening of antiproliferative drugs," Journal of Pharmacological Methods, vol. 12, no. 1, pp. 69-78, 1984.

[76] J. R. Wolter, "Diabetic retinopathy," American Journal of Ophthalmology, vol. 51, no. 5, pp. 1123-1141, 1961.

[77] D. A. Antonetti, A. J. Barber, S. K. Bronson et al., "Diabetic retinopathy: seeing beyond glucose-induced microvascular disease," Diabetes, vol. 55, no. 9, pp. 2401-2411, 2006.

[78] K. Yamamoto, K. Maruyama, N. Himori et al., "The novel Rho kinase (ROCK) inhibitor K-115: a new candidate drug for neuroprotective treatment in glaucoma," Investigative Ophthalmology \& Visual Science, vol. 55, no. 11, pp. 7126-7136, 2014.

[79] H. Song and D. Gao, "Fasudil, a Rho-associated protein kinase inhibitor, attenuates retinal ischemia and reperfusion injury in rats," International Journal of Molecular Medicine, vol. 28, no. 2, pp. 193-198, 2011. 
[80] K. Zhang, L. Zhang, and R. N. Weinreb, "Ophthalmic drug discovery: novel targets and mechanisms for retinal diseases and glaucoma," Nature Reviews. Drug Discovery, vol. 11, no. 7, pp. 541-559, 2012.

[81] S. Nakao, M. Arima, K. Ishikawa et al., "Intravitreal anti-VEGF therapy blocks inflammatory cell infiltration and re-entry into the circulation in retinal angiogenesis," Investigative Ophthalmology \& Visual Science, vol. 53, no. 7, pp. 4323-4328, 2012.

[82] L. P. Aiello, E. A. Pierce, E. D. Foley et al., "Suppression of retinal neovascularization in vivo by inhibition of vascular endothelial growth factor (VEGF) using soluble VEGFreceptor chimeric proteins," Proceedings of the National Academy of Sciences of the United States of America, vol. 92, no. 23, pp. 10457-10461, 1995.

[83] T. Murata, K. Nakagawa, A. Khalil, T. Ishibashi, H. Inomata, and K. Sueishi, "The relation between expression of vascular endothelial growth factor and breakdown of the blood-retinal barrier in diabetic rat retinas," Laboratory Investigation, vol. 74, no. 4, pp. 819-825, 1996.

[84] S. Ishida, T. Usui, K. Yamashiro et al., "VEGF164 is proinflammatory in the diabetic retina," Investigative Ophthalmology \& Visual Science, vol. 44, no. 5, pp. 2155-2162, 2003.

[85] M. Saint-Geniez, A. S. Maharaj, T. E. Walshe et al., "Endogenous VEGF is required for visual function: evidence for a survival role on muller cells and photoreceptors," PloS One, vol. 3, no. 11, article e3554, 2008.

[86] Y. Murakami, Y. Ikeda, Y. Yonemitsu et al., "Inhibition of choroidal neovascularization via brief subretinal exposure to a newly developed lentiviral vector pseudotyped with Sendai viral envelope proteins," Human Gene Therapy, vol. 21, no. 2, pp. 199-209, 2010.

[87] Y. Kitaoka, Y. Kitaoka, T. Kumai et al., "Involvement of RhoA and possible neuroprotective effect of fasudil, a Rho kinase inhibitor, in NMDA-induced neurotoxicity in the rat retina," Brain Research, vol. 1018, no. 1, pp. 111-118, 2004.

[88] A. Hirata, M. Inatani, Y. Inomata et al., "Y-27632, a Rhoassociated protein kinase inhibitor, attenuates neuronal cell death after transient retinal ischemia," Graefe's Archive for Clinical and Experimental Ophthalmology, vol. 246, no. 1, pp. 51-59, 2008.

[89] K. Hollanders, I. Van Hove, J. Sergeys et al., "AMA0428, a potent Rock inhibitor, attenuates early and late experimental diabetic retinopathy," Current eye Research, vol. 42, no. 2, pp. 260-272, 2017. 


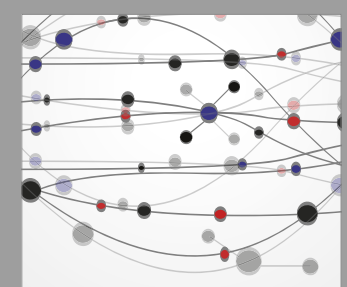

The Scientific World Journal
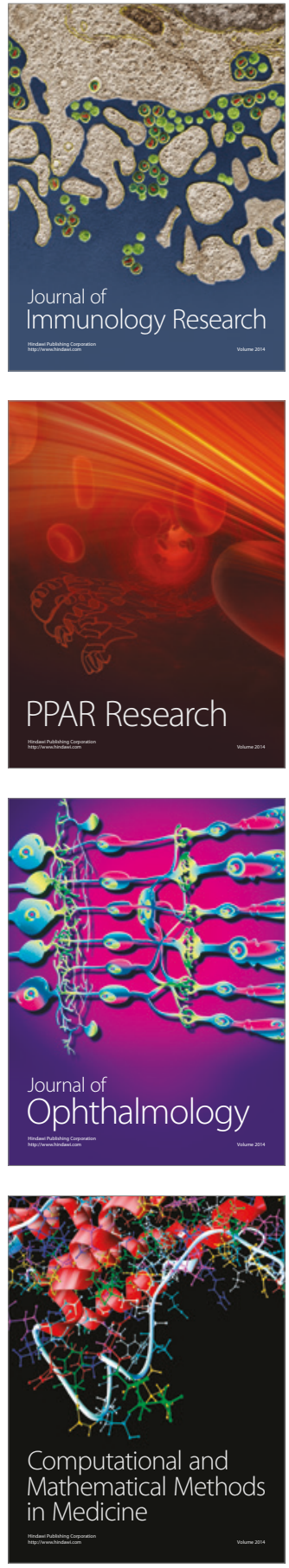

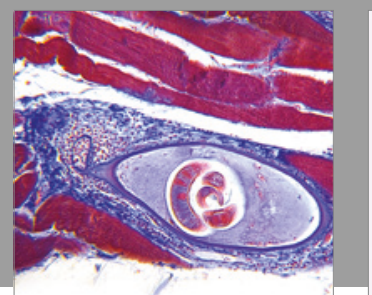

Gastroenterology Research and Practice
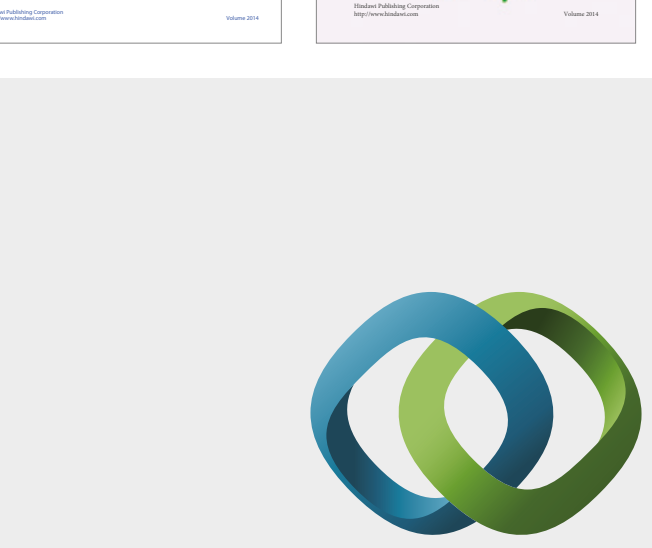

\section{Hindawi}

Submit your manuscripts at

https://www.hindawi.com
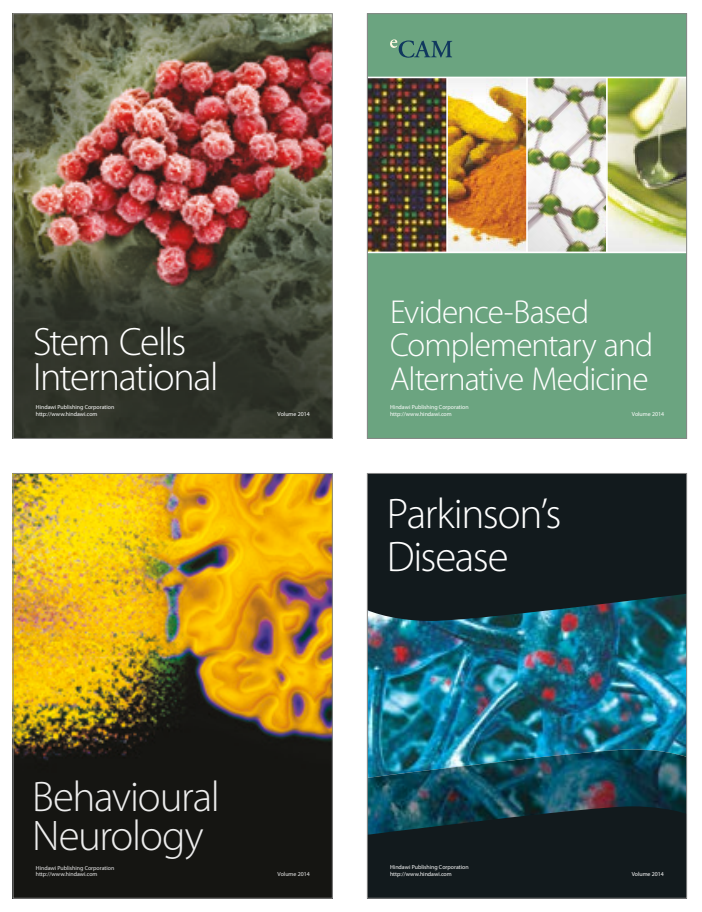
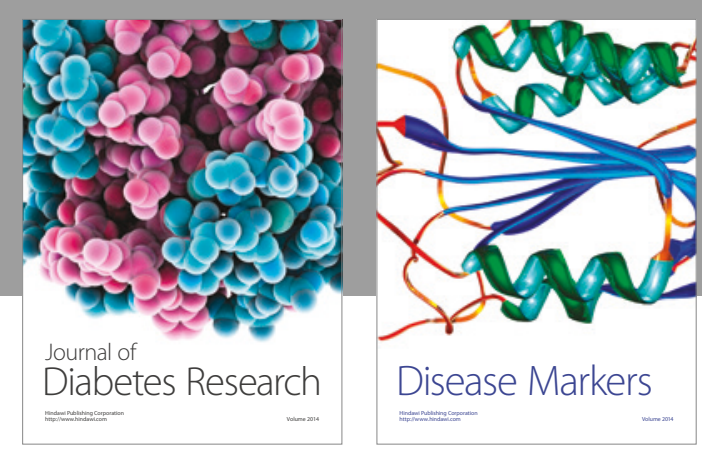

Disease Markers
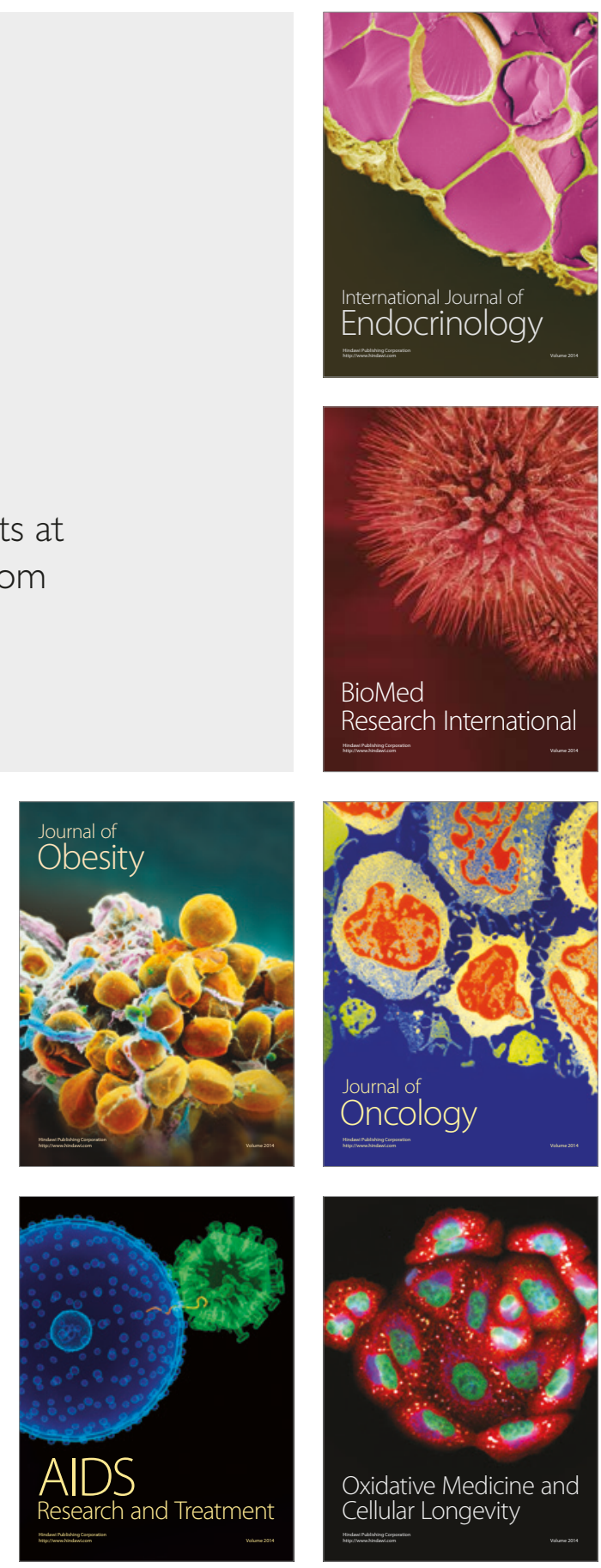